\title{
Guinea pig versus computer mouse in post graduate practical pharmacology
}

\author{
Allen Joe Rodrigues, Laxminarayana Kamath*
}

Department of Pharmacology, Bangalore medical College and Research institute, Bangalore, India

Received: 13 December 2016 Accepted: 03 January 2017

\section{*Correspondence to:}

Dr. Laxminarayana Kamath, Email:

koteshwarkamath@yahoo.com

Copyright: (C) the author(s), publisher and licensee Medip Academy. This is an openaccess article distributed under the terms of the Creative Commons Attribution NonCommercial License, which permits unrestricted noncommercial use, distribution, and reproduction in any medium, provided the original work is properly cited.

\begin{abstract}
Background: Pressures from animal right organizations like PETA lead to stringent animal handling guidelines by CPCSEA, UGC, MCI which resulted in limitation of animal experiments in postgraduate practical pharmacology. So, this study is designed to know the perceptions and alternative suggestions of pharmacology postgraduate students about animal experiments in their practical curriculum.

Methods: 127 pharmacology postgraduate students who participated southern regional conference of IPS -2016 at Belgaum, Karnataka were included in this questionnaire based study. The data was analysed using descriptive statistics.

Results: Majority 79\% students favoured animal experiments even though only $53 \%$ of students were conducting animal experiments at their institute. Some of the reasons quoted by the students to favour animal experiments were, provide better understanding of drug effects $(66 \%)$, interested in preclinical research \& drug development $(60 \%)$, provides hands on experience $(56 \%)$ etc. Some of the virtual experiments suggested by students which can be used in parallel to animal experiments to reduce animal sacrifice were computer simulated animal experiments $(78 \%)$, preformed graphs/charts $(65 \%)$, video films $(53 \%)$ and so on. Main reasons to like CAL were effects of drug can be clearly visualized (72\%), can be repeated (63\%), avoids error (57\%), saves time (54\%) etc.

Conclusions: There is a need to incorporate CAL along with continuation of animal experiments in postgraduate practical pharmacology, so that both will compliment, enhance, reinforce the learning from each other and also drastically reduce the number of animals sacrificed.
\end{abstract}

Keywords: Animal experiments, Computer assisted learning (CAL), Students

\section{INTRODUCTION}

Animal experiments which includes the demonstration of drug effects on tissues or whole animal are an essential component of post graduate practical pharmacology. ${ }^{1}$ However, because of pressures from animal right organisations with subsequent guidelines by CPCSEA (Committee for the purpose of control and supervision of experiments on animals), UGC, Supreme court ban on animal experiments in educational institutions have seriously limited animal use in post graduate practical pharmacology. ${ }^{2-4}$

Students are important stake holders who can provide valuable feedback about their training. ${ }^{5}$ A number of feedback studies conducted on undergraduate medical students have confirmed the effectiveness of Computer assisted learning (CAL) in terms of meeting learning objectives with additional advantages when compared to animal experiments. ${ }^{6-8} \mathrm{CAL}$ has now become an integral component of undergraduate practical pharmacology curriculum. $^{9-11}$ But no such feedback studies were conducted among postgraduate pharmacology students.

As an alternative to animal experiments computer assisted learning has been increasingly implemented by several medical schools across the world including India. ${ }^{9}$ In 2009, Medical council of India officially amended its bachelor of medicine and bachelor of surgery (MBBS) regulations to state that experimental work on animals can be demonstrated by computer aided education. ${ }^{12}$ But to date there is no clear cut guidelines for conducting 
animal experiments in post graduate pharmacology practical and it is a topic of debate.

Considering all these facts this study is undertaken to know the perceptions and suggestions of postgraduate pharmacology students about various aspects of animal experiments and alternative to it.

\section{METHODS}

The present study was conducted in January 2016 at southern regional conference of Indian pharmacological society held at Belagavi institute of medical sciences, Belagavi, Karnataka. After obtaining permission from organising secretary a total of 127 pharmacology post graduate students were included in this questionnaire based study. A structured validated questionnaire was developed consisting of eight questions having options and a space for suggestion/remarks.

The students were permitted to indicate more than one option for the questions asked. The questions explored various aspects of animal experiments and also provided a platform for expressing views on alternatives. A brief explanation was given about the questionnaire before it was handed over to post graduates in pharmacology. The participants were asked to be truthful and unbiased in answering the question. They were asked not to reveal their identities to ensure freedom of expression. The data was analysed using descriptive statistics.

\section{RESULTS}

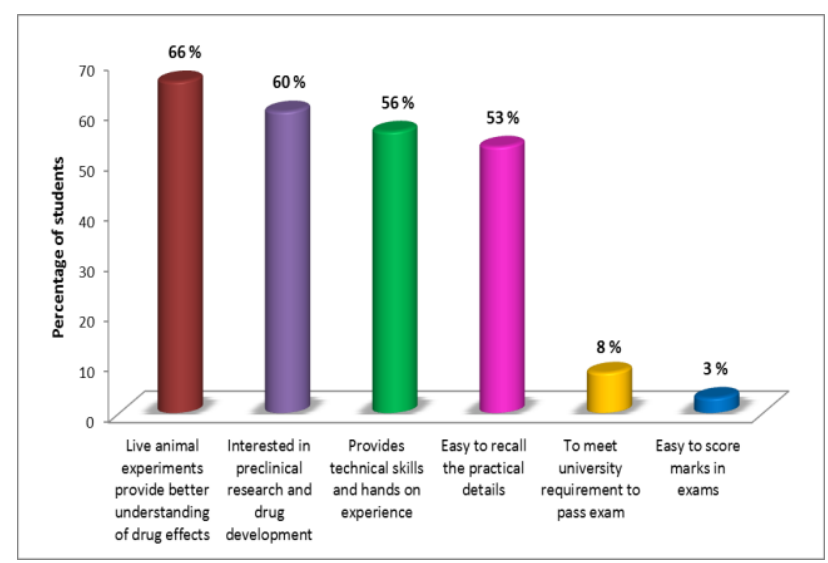

Note: The total percentages may not be 100 as students could choose multiple answers

\section{Figure 1: Reasons to favour animal experiments.}

All the 127 students who enrolled in the study completed the questionnaire. An overwhelming majority of students favoured animal experiments (100/127; 79\%) even though only $67 / 127 ; 53 \%$ of the students were conducting animal experiments at their institute. Some of the reasons quoted by the students to favour animal experiments were, provide better understanding of drug effects (84/127; 66\%), interested in preclinical research \& drug development $(76 / 127 ; 60 \%)$, provides hands on experience $(71 / 127 ; 56 \%)$ etc. (Figure 1$)$.

A minority of students disfavoured animal experiments (27/127; 21\%). Reasons for not favouring animal experiments were, repetition of already established facts $(27 / 127 ; 21 \%)$, unpredictability of getting results $(23 / 127 ; 18 \%)$, ethical issues $(19 / 127 ; 15 \%)$ etc. (Figure 2).

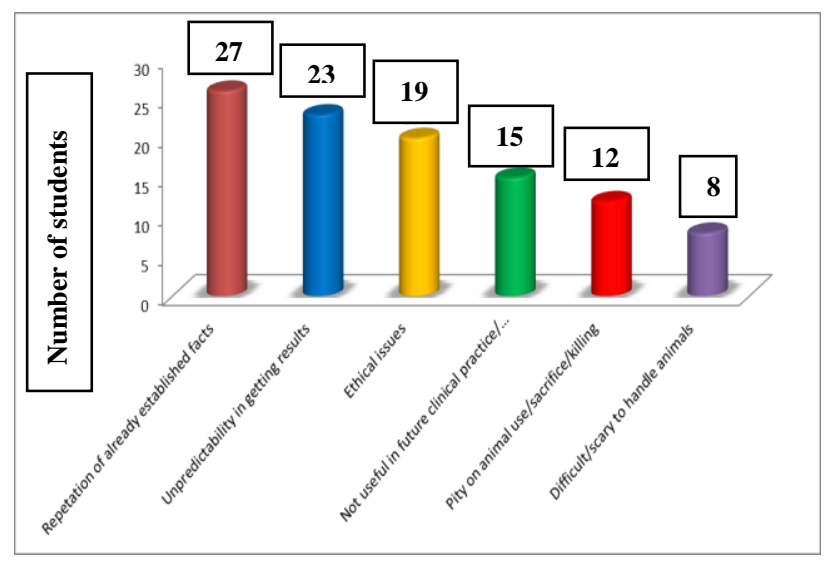

Figure 2: Reasons to disfavour animal experiments.

Some of the virtual experiments suggested by students which can be used in parallel to animal experiments to reduce animal sacrifice were computer simulated animal experiments $(99 / 127 ; 78 \%)$, preformed graphs/charts $(82 / 127 ; 65 \%)$, video films $(67 / 127 ; 53 \%)$ and so on (Figure 3). Main reasons to like CAL were effects of drug can be clearly visualized $(91 / 127 ; 72 \%)$, can be repeated $(80 / 127 ; 63 \%)$, avoids error $(72 / 127 ; 57 \%)$, saves time $(69 / 127 ; 54 \%)$ etc. which is shown in Table 1.

Table 1: Reasons to prefer CAL -Computer simulated animal experiments as a supplement to animal experiments.*

\begin{tabular}{|lcc|}
\hline Reasons & n & $\%$ \\
\hline $\begin{array}{l}\text { Effect of drugs can be clearly visualized } \\
\text { by computer simulations }\end{array}$ & 91 & $72 \%$ \\
\hline $\begin{array}{l}\text { When used to train prior to live } \\
\text { experiments can reduce the number of } \\
\text { animals }\end{array}$ & 89 & $70 \%$ \\
\hline Can be repeated as many times as required & 80 & $63 \%$ \\
\hline $\begin{array}{l}\text { Errors in live experiments can be avoided } \\
\text { by computer simulation }\end{array}$ & 72 & $57 \%$ \\
\hline $\begin{array}{l}\text { Cal saved time when compared to live } \\
\text { experiments }\end{array}$ & 69 & $54 \%$ \\
\hline $\begin{array}{l}\text { Overcome ethical issues related to animal } \\
\text { experiments }\end{array}$ & 69 & $54 \%$ \\
\hline
\end{tabular}

Majority of postgraduate students (120/127; 95\%) who participated favoured that feedback is necessary to 
bring about educational innovations and curricular reforms.

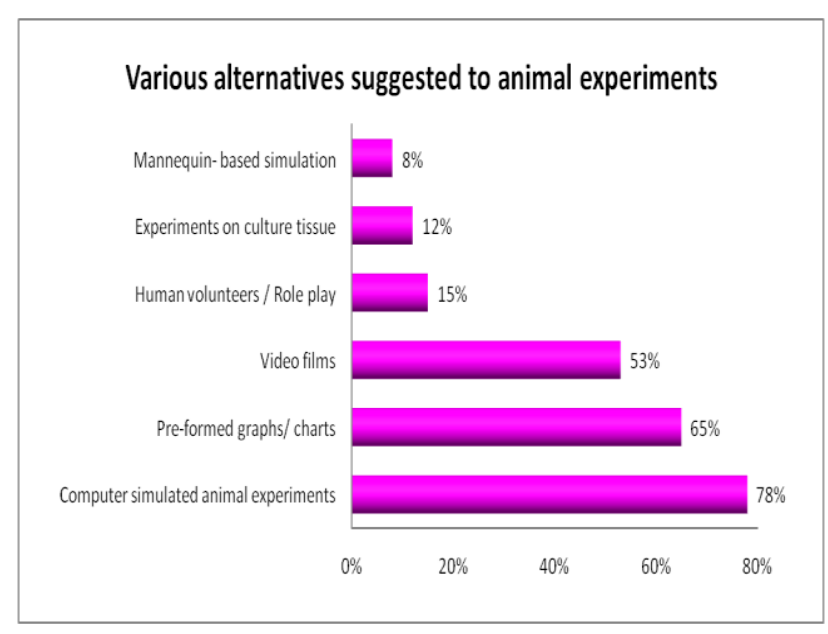

\section{Figure 3: Various virtual experiments suggested as a supplement to animal experiments.}

\section{DISCUSSION}

Out of the 127 students who participated in the study only $53 \%$ were conducting animal experiments at their institute. But a majority (73\%) favoured animal experiments in postgraduate practical pharmacology. On the contrary in many similar such studies involving undergraduate medical students majority felt animal experiments can be discontinued with virtual experiments as alternative. ${ }^{6-8}$ Authors are of the opinion that undergraduate students do not require the skills of dissection and setting up of experiments in their later years of medical practice. But the same is not true for post graduates in pharmacology. These skills are very much necessary irrespective of whether they get employed in a research /academia/industry. Careers in pharmaceutical industry where animals are used in drug development need skills in animal experimentation. Preclinical safety and efficacy data on animals is a must for submission to drug regulatory authorities before the permission for clinical trials in humans granted. ${ }^{2}$ So, there is a need of professionals with animal handling and dissection skills. This talent pool can be created by continuing animal experiments for research aspects of postgraduate practical pharmacology.

Overwhelming majority of postgraduate students felt that the live animal experiments provide opportunity to develop technical skills and gain hands on experience of individual technique with better understanding of the topic as well as ability to recall. Also the authors feel that animal dissection provides the learner with real material and experience as no alternative could fully replace live animal use in education. But at the same time the animals used in experiments should not be considered as dispensable tools, their judicious use is a must with application of 3R concept proposed by Russel and Burch so as to minimize the pain and distress to animals. ${ }^{13}$ In this context, it is worth to note that $78 \%$ of the students suggested simultaneous use of CAL along with live animal experiments. Similar suggestion was seen with studies done by Gibbon et al, Toth et al, Dantas et al, Franklin et al. ${ }^{14-17}$ The authors feel that CAL (virtual laboratories) can be used before live animal experiments as preparation for the later. So, they complement and enhance the learning from each other. This will be a good move towards the goal of achieving three $\mathrm{R}$ conceptsreduce, refine and replace animal experimentation. Some of the other virtual experiments as a supplement to animal experiments suggested by postgraduate students were preformed graphs, video films, human volunteers, culture tissue, mannequin etc. Virtual teaching reduces animal use, total investment, space, equipment and faculty time.

Some of the advantages of CAL mentioned by students in our study are CAL gives a better understanding of the topic, reduces animal use, clear estimation of drug effects, errors in experiments can be reduced, can be repeated, saves time, avoids ethical issues related to animal experiments. These study results match with many other well executed studies. ${ }^{6,7,9,11,18}$ Many studies endorsed the fact that both live animal experiments and CAL are equally effective in knowledge acquisition and meeting learning objectives. ${ }^{9,14}$ Also CAL in medical education has been implemented by $95 \%$ of medical schools in US and $100 \%$ medical schools in Canada and UK. ${ }^{9}$ Even though CAL requires technical knowledge of computers, expensive software, prefixed doses which hinder students to observe biological response at desired doses, its advantages outweigh the disadvantages.

Leading drug discoveries in the past were possible due to experimentation on animals. The CPCSEA guidelines, clearly instructs that animal experiments shall not be performed for the sole purpose of attaining skills. Authors are of the opinion that CAL should be used parallel to animal experiments even in postgraduate pharmacology, whenever the effects of a drug which is conclusively known and animal experiments can be reserved for research aspects of post graduate pharmacology. The students also need to be made aware of the CPCSEA rules and regulations on animal experimentation. ${ }^{3}$ Also in our study $21 \%$ of students disfavoured animal experiments quoting reasons such as repetition of already established facts, unpredictability in getting results, ethical issues, not useful in future clinical practice, pity on animal sacrifice, scary to handle animals. Authors also are of the opinion that students can be given a choice to use alternatives to dissection. In this context it is worth to note that several states of USA have passed choice in dissection laws. ${ }^{2}$ Meanwhile animal use for training purpose should be delayed until a student decides to pursue a research carrier which involves animal experimentation. 


\section{CONCLUSION}

Animal experiments still play a role in drug development. In the absence of clear guidelines there are concerns in continuing animal experiments in postgraduate practical pharmacology. Computer simulated experiments when fully integrated alongside live animal experiments each compliment, reinforce and enhance learning from other. In this regard regulatory bodies like the MCI, CPCSEA, UGC, ICMR together along with consultation of all stakeholders involved should finalize uniform guidelines for conducting animal experiments along with virtual experiments in postgraduate practical pharmacology. Also feedback from students must be examined with great deliberation while formulating guidelines.

\section{ACKNOWLEDGEMENTS}

We wish to thank all the postgraduate students who have participated in this study.

\section{Funding: No funding sources}

Conflict of interest: None declared

Ethical approval: Not required

\section{REFERENCES}

1. Badyal DK, Desai C, Tripathi SK, Dhaneria SP, Chandy SJ, Bezbaruah BK. Postgraduate pharmacology curriculum in medical institutions in India: time for need-based appraisal and modifications. Indian J Pharmacol. 2014;46(6):584-9.

2. Badyal DK, Desai C. Animal use in pharmacology education and research: The changing scenario. Indian J Pharmacol. 2014;46(3):257-65.

3. Committee for the purpose of control and supervision of experiments on animals (CPCSEA). Available from: http://moef.nic.in/modules/divisions/cpcsea/ [Last accessed on 2013 May 25].

4. Guidelines for discontinuation of dissection and animal experimentation in zoology/ life sciences in a phased manner, 2011. University Grants Commission. Available from: http://www.gujaratuniversity.org.in/web/NWD/News Events/8999_UGC\%20 Guidelines\%20for\%2.

5. Thirunavukkarasu J, Babu CS, Tharani CB. A Study on Effectiveness of Different Teaching Methodology in Pharmacology for Under Graduate Students. 2011;2(3):487-92.

6. Saurabh MK, Agrawal J. International Journal of Basic \& Clinical Pharmacology The opinion of undergraduate medical students on current curriculum and teaching methodology of pharmacology in four medical colleges of India: A questionnaire based study. Int $\mathrm{J}$ Basic Clin Pharmacol. 2015;4(5):970-5.
7. Tikoo D, Gupta M. Student's perception and experience of computer assisted learning as a teaching method in experimental pharmacology. Int $\mathbf{J}$ Basic Clin Pharmacol. 2015;4(6):1168-74.

8. Babu CS, Latha K, Thirunavukkarasu J, Tharani CB. $P$ Harmacology $V$ Irtual $E$ Xperimental $P$ Harmacology and an Lternative or N Ot ? - a G Lobal a Ssessment By P Harmacology F Aculties and Mbbs. 2011;3(10):25-9.

9. John LJ. A review of computer assisted learning in medical undergraduates. J Pharmacol Pharmacother. 2013;4(2):86-90.

10. Raveendran R, Batmanabane G. Alternatives to Animals in Teaching: Experience in an Indian Medical School. 2000:355-60.

11. Nettath S. Computer assisted learning (CAL) as a teaching learning method in teaching experimental pharmacology. Int $\mathbf{J}$ Basic Clin Pharmacol. 2014;3(1):63.

12. Medical Council of India. Medical council of India, New Delhi, amendment notification of 8 July 2009 to the Minimal standard requirements for medical colleges with 150 admissions annually, regulations, 1999; Available from: http://www.mciindia.org/helpdesk/how_to_start/STA NDARD FOR 150.pdf

13. Richmond J. Refinement, reduction, and replacement of animal use for regulatory testing: future improvements and implementation within the regulatory framework. ILAR J. 2002;43(1):S63-8.

14. Gibbons NJ, Evans C, Payne A, Shah K, Griffin DK. Computer simulations improve university instructional laboratories. Cell Biol Educ. 2004;3(4):263-9.

15. Toth EE, Ludvico LR, Morrow BL. Blended inquiry with hands-on and virtual laboratories: the role of perceptual features during knowledge construction. Interact Learn Environ. 2014;22(5):614-30.

16. Dantas AM, Kemm RE. A blended approach to active learning in a physiology laboratory-based subject facilitated by an e-learning component. Adv Physiol Educ. 2008;32(1):65-75.

17. Franklin S, Peat M, Lewis A. Virtual versus traditional dissections in enhancing learning: A student perspective. In: Australasian Society for Computers in Learning in Tertiary Education; 2001.

18. West J, Veenstra A. Cane toad or computer mouse? Real and computer-simulated laboratory exercises in physiology classes. Aust J Educ. 2012;56(1):56-67.

Cite this article as: Rodrigues AJ, Kamath L. Guinea pig versus computer mouse in post graduate practical pharmacology. Int J Basic Clin Pharmacol 2017;6:441-4. 